\title{
Lógica (nota sobre a dialética do ser e do nada no devir)
}

\author{
Paulo Vieira Neto
}

\begin{abstract}
RESUMO: Este artigo tem por objetivo apontar, na lógica do ser, uma confusão entre ser e nada indeterminados e determinados na construção do argumento pelo qual Kant refutava a prova ontológica da existência de Deus. Todavia, o desenvolvimento da resposta hegeliana aponta para algo além disso. O segredo da infinitude ultrapassa a lógica do ser, para exprimir-se no vínculo entre Noção e efetividade. Claramente, tal vínculo conduz a maneira como a lógica irá pensar o absoluto - daí a conexão íntima com o problema envolvido na provas da existência de Deus.
\end{abstract}

Palavras-chave: Hegel; Kant; Dialética; Lógica; Absoluto

\begin{abstract}
This article aims to point out, in the logic of being, a confusion between being and nothing undetermined and determined to build the argument by which Kant refuted the ontological proof of God's existence. However, the development of Hegel's reply points to something beyond that. The secret of infinity exceeds the logic of being, to express itself in the bond between Concept and effectiveness. Clearly, this bond leads the way and how the logic will think the absolute - hence the up close connection with the problem involved in the proofs of the existence of God.
\end{abstract}

Key-words: Hegel; Kant; Dialectic; Logic; Absolut

Quando se pressupõe um certo conteúdo, uma existência determinada, então esta última, por ser tal, é em uma relação múltipla com outros conteúdos; e não é indiferente por si mesmo que seja ou não um outro conteúdo dentre os quais esta existência estava em relação, porque é precisamente por essa relação que aquela última era essencialmente o que era.

Eis o aviso que Hegel dirige ao leitor que se permitisse, depois da leitura da dialética do ser, do nada e do devir, dizer para si mesmo algo como:

“Ser e não ser são o mesmo, assim, é o mesmo que esta casa seja ou não seja ou

\footnotetext{
1 "Wenn ein bestimmter Inhalt, irgend ein bestimmtes Daseyn vorausgesetzt wird, so ist diess Daseyn, weil es bestimmtes ist, in mannigfaltiger Beziehung auf anderen Inhalt; es ist fuer dasselbe nicht gleichgueltig, ob ein gewisser anderer Inhalt, mit dem es in Beziehung steht, ist oder nicht ist; denn nur durch solche Beziehung ist es wesentlich das, was es ist.” WL, I, B, R1, SL 86
} 
que estes cem táleres sejam ou não parte de minha fortuna.

A remissão imediata ao famoso exemplo kantiano, fornecido pela Crítica da Razão Pura no capítulo sobre a dialética própria às provas da existência de Deus, não é casual, é claro. Mesmo porque o mau humor hegeliano, no que diz respeito a esse exemplo, é notório. Todavia, nas passagens em questão, todo o problema tem a ver com uma canhestra manobra kantiana - segundo Hegel uma "verworrene Schwerfaelligkeit" ${ }^{2}$. Trata-se de transitar entre o ser e o não-ser sem levar em consideração se estes últimos eram tomados em um significado determinado, ou entendidos em geral. Na verdade, o exemplo kantiano confunde por ignorar a refração do ser e do não-ser em uma ampla gama de significados diferentes (positivo e negativo; real e aparente; existente e meramente possível, e assim por diante). Refração inevitável, mas, digna de consideração quando se passa do pensamento do ser e do não ser em geral para o de um ser e um não-ser específicos como os de cem táleres ou de uma casa.

É que ao se adotar o ser e o não ser em toda sua imediatez e pureza ainda não se pode partir daí para alguma relação explícita entre essência e existência, e, ao contrário, quando pensamos uma existência determinada, dotada de conteúdo portanto, a determinação mesma já pressupõe uma relação entre as duas coisas "porque é precisamente por essa relação que aquela última <a existência determinada $>$ era essencialmente o que era”. Assim, a relação entre os cem táleres e uma fortuna determinadas não é indiferente à existência efetiva dos primeiros, quando os pensamos como realizados, todavia, a relação entre os cem táleres e sua existência segue uma outra lógica.

Uma boa porção da primeira nota à dialética do ser do devir e do nada, tenta desbaratar essa confusão. Cabe examinar seu desenvolvimento.

O ponto reside numa distinção entre ser e nada em geral, ou entre ser e não-ser determinados, operada pelo argumento kantiano. A descrição sumária da prova retoma os lugares comuns da versão moderna, pós-cartesiana, do argumento: a existência de

\footnotetext{
2 WdL I, 1, anm 1
} 
Deus decorre da necessidade contida no conceito de um ente (Wesen) possuidor de todas as realidades (Realitaeten), e dentre essas realidades a existência (Existenz) ela própria. O nervo do contra-argumento kantiano, ainda segundo Hegel, estaria em que ser (seyn, significando existir, na acepção latina de esse) não é uma determinação de conteúdo do que é, o que equivale a afirmar: 1) que a existência ou o ser (esse) não é uma propriedade ou um predicado real ou ainda 2) que o ser nesse significado não implica o conceito de algo passível de ser adicionado a outro conceito de alguma coisa $^{3}$ - o esse, nesse sentido, parece ser incomensurável com o conceito.

Conseqüência imediata disso, ainda segundo Hegel, está em que Kant possa afirmar que o possível - o ser em significado existencial, mas afetado apenas de possibilidade - não possui nada a menos que o efetivo (wirkliche), isto é: nada a menos em sua determinação de conteúdo; de forma tal que cem táleres possíveis e cem efetivos, em suas determinações de conteúdo, não diferem em nada. Passando a limpo: as determinações de conteúdo de algo, como os cem táleres do exemplo, não são afetadas pela diferença entre ser e não-ser, tomado o verbo em seu significado existencial, estão aquém e, por força disso, permanecem imunes a essa diferença. $\mathrm{O}$ impacto do exemplo kantiano, no entanto, está no contraste a ser operado a partir daí: considere-se a diferença efetiva que os cem táleres fariam uma vez incorporados à minha efetiva fortuna, que, ao contrário, não seria acrescida com cem táleres possíveis em termos mais técnicos: o aumento no saldo causado pelo depósito efetivo de cem táleres é uma ligação sintética entre o conceito de minha fortuna e o conceito de cem táleres, mas, o que é fundamental, essa síntese, como a de um juízo sintético a posteriori, pressupõe a efetividade se realizando.

Somente nesse último caso faria diferença a efetividade do depósito de cem táleres porque, sem ela, não se adicionaria nada, sinteticamente, ao conceito de minha fortuna. É verdade que posso pensar minha fortuna sendo (em sentido existencial) cem táleres maior; sim, mas, diz Kant, ela só será (efetivamente) cem táleres maior ... com o efetivo depósito. A diferença inefável entre os dois casos deve-se ao fato de haver um mundo assim (ou um mundo no qual houve o efetivo depósito numa conta efetiva).

\footnotetext{
${ }^{3}$ Hegel cita a passagem da Crítica da Razão Pura que está resumindo: KrV, B 628 e ss..
} 
Ora, compreendendo assim a interpretação que Hegel faz do exemplo, nesse ponto da Ciência da Lógica, fica mais clara a advertência que se segue:

Embora a Noção seja claramente diferente do ser, ainda há uma diferença maior entre Deus, os cem táleres e outras coisas finitas. É por definição das coisas finitas que nelas a Noção seja diferente do ser, que Noção e realidade, alma e corpo, sejam separáveis e então, perecíveis e mortais ${ }^{4}$.

A impertinência do contra-argumento, aos olhos de Hegel, mostra toda sua amplitude quando se dá conta da correta diferença entre finito e infinito. Claro que não se trata aqui, apenas, de negociar um aumento para o valor da aposta: um número indefinido de táleres não seria suficiente para transpor a barreira entre o finito e o infinito. O exemplo kantiano é categorialmente inadequado.

Resuma-se o percurso até aqui: a primeira nota da lógica do ser apontava uma confusão entre ser e nada indeterminados e determinados na construção do argumento pelo qual Kant refutava a prova ontológica da existência de Deus. Todavia, o desenvolvimento da resposta hegeliana aponta para algo além disso.

Primeiro, que é preciso reconsiderar o jogo de categorias lógicas envolvidas na prova kantiana, esclarecendo não somente o que Kant pretendia dizer, mas o que ele efetivamente pôde dizer, sob a guarda, agora, das lições que a lógica do ser impõe ao discurso mesmo sobre a existência e demais temas metafísicos (sem detrimento, por exemplo, das reflexões que a lógica da essência irá operar sobre as mesmas categorias).

Depois, que a refutação da prova ontológica, como levada a cabo por Kant, desconsidera uma maneira de pensar o infinito, pelo menos, nos termos da lógica hegeliana ela mesma. Isso é: a boa compreensão da prova ontológica exige que o exame do ser, da essência e do conceito alcance a revisão do nexo entre finito e infinito, mas sobretudo, leve a pensar este último em termos bastante distintos daqueles de que se usava para pensar o finito.

\footnotetext{
${ }^{4}$ WL, I, B, R1, SL 87.
} 
Por fim, que o segredo da infinitude ultrapassa a lógica do ser, para exprimir-se no vínculo entre Noção e efetividade. Claramente, tal vínculo conduz a maneira como a lógica irá pensar o absoluto - daí a conexão íntima com o problema envolvido na provas da existência de Deus. Daí também o interesse incontido em criticar justamente a refutação dessa prova como oferecida por Kant. De fato, não se trata de refutar o kantismo, mas de ultrapassá-lo numa direção que ele mesmo apontava. A dialética transcendental se punha como sua tarefa criticar a pretensão da razão teórica em postular-se capaz de, nesse registro, cuidar de objetos de estatura e de natureza semelhantes às de Deus, da liberdade e da totalidade do mundo. A dialética hegeliana não reabilita essa pretensão nos termos da metafísica tradicional, por certo, mas, provocativamente, retoma esses objetos no pensamento do absoluto.

Cabe saber como.

A questão que se dirige ao hegelianismo, neste momento, passa a ser a seguinte: como, a partir de Kant, ultrapassar o limite da dialética transcendental, sem retornar ao velho dogmatismo? Questão que é coextensa (e talvez possa ser traduzida na seguinte): como reconstruir a passagem do finito ao infinito sem conceder à sua posição meramente subjetiva ou objetiva? Ou ainda: como pensar o absoluto?

No entanto, um detalhe da argumentação hegeliana não pode ser desconsiderado, sobretudo para quem se põe essa tarefa ambiciosa. O comentário que Hegel faz à refutação da prova ontológica, a partir de seu famoso exemplo, não pretende simplesmente voltar à posição que estava sendo refutada por Kant. Não se trata de opor-se a Kant tese a tese, palmilhando sua filosofia em sentido contrário. Hegel, com sua contra-argumentação impõe uma escolha pelo começo da lógica, e essa escolha se justifica precisamente pela confusão causada a partir do exemplo kantiano. Assim, quando retornamos à diferença entre ser e não ser determinados e ser e nada em geral, nos deparamos com a tarefa de pensar o ser e o nada, primeiro, em suas formas mais abstratas, imediatas e puras. 
Quando a lógica recita "Ser, puro ser ..." a pureza implica a ausência imediata de qualquer determinação, o que vale para o nada também. Mas, por trás disso está o afastamento da atitude que tacitamente concedia haver um mundo diante do conceito que pressentia apenas esse haver imediato sob a forma inefável da efetividade. Agora tudo está em jogo no desenvolvimento mesmo do conceito. E, se é verdade que apenas por volta da Lógica da Essência poderemos discutir novamente o argumento kantiano e desfazer mais uma parte de sua "verworrene Schwerfaelligkeit", já na escolha de seus primeiros passos a Lógica acorrentou o pensamento a uma atitude distinta - aliás, tanto quanto já o pretendia fazer Fichte, por exemplo, na Exposição da Doutrina da Ciência em 1794.

Entenda-se bem: a ingenuidade de quem responde à dialética do ser e do nada e no devir é já um compromisso com a posição de um fato não tematizável, a existência que empresta efetividade diante de um conceito que, de outra forma, não a significa jamais. Duas formas de idealismo que diferem sutil mas profundamente. A primeira, a kantiana, exige o plano do fato como ponto de partida para operar a adequação do conceito ou, melhor ainda, da razão, a seus limites factuais. A segunda dissolve a distinção fato-direito na imanência do conceito - não sem um longo trabalho de dissolução, por certo. Ora, é o segundo idealismo, não por acaso, que pode tomar por natural a tarefa de pensar até o absoluto por ter começado a pensar a partir da abstração mais completa: sua aposta é a de que o conteúdo do pensamento se concilie com ele na imanência mesma de seu desenvolvimento. 